\title{
v. 8, n. 1 (2015)
}

\section{EXPEDIENTE}

\section{Centro Universitário de Belo Horizonte UniBH}

Reitoria

Msc. Vânia Amorim Café de Carvalho

Diretoria do Núcleo Acadêmico

Msc. Silvana Alves de Oliveira

Diretoria do Instituto de Engenharia e Tecnologia IET

Msc. Joaquim José da Cunha Júnior

\section{Revista e-xacta}

Conselho Editorial

Dr. Vitorio Delogo de Castro - Editor Geral

Dra. Magali Maria de Araújo Barroso

Dra. Ana Paula Ladeira

Dr. Bráulio Roberto Gonçalves Marinho Couto

Msc. Joaquim José da Cunha Júnior

Dra. Maria Elena Walter

Dr. Anderson Pimentel Borges

Karen Olimme

\section{Conselho Científico}

Dra. Adriana Maria Tonini (UFOP)

Dr. Adriano Aguiar Mendes (UFSJ)

Dr. Alessandro Vivas Andrade (UFVJM)

Dr. Alexandre Magno Alves Diniz (PUC Minas)

Dr. Alfio Conti (UFOP)

Dra. Ana de Oliveira Rodrigues (UNA)

Dra. Cibele Tosin Stroppa (UniBH)

Dr. Danilo Pereira Pinto (UFJF)
Dr. Dimas Felipe de Miranda (PUC Minas)

Dra. Diva de Souza e Silva Rodrigues (IBGE, UniBH)

Dr. Edmilson Rodrigues Pinto (UFU)

Dra. Eliane Scheid Gazire (PUC Minas)

Dr. Frederico da Silva Reis (UFOP)

Dr. Guilherme Tavares Assis (UFOP)

Dr. Gustavo Fernandes Rodrigues (UFSJ)

Dr. Henrique Pacca Loureiro Lunna (UFAL)

Dr. João Francisco de Abreu (PUC Minas)

Dra. Lúcia Peret de Almeida (Uni-BH)

Msc. Luciana Maria Tenuta de Freitas (UniBH)

Dra. Maria Aparecida Vieira Teixeira Garcia (UFMG)

Dr. Moacir de Souza Júnior (UFSJ)

Dra. Renata Carolina Zanetti Lofrano (UFSJ)

Dr. Rogério Alexandre Alves de Melo (UFVJM)

Dr. Ronald Arreguy Silva (UniBH)

Dra. Sandra Maria Antunes Nogueira (UFOP)

Dra. Sílvia Mendonça Vieira (UFOP)

Dra. Sinthya Gonçalves Tavares (UniBH)

Dra. Sônia Denise Ferreira Rocha (UFMG)

Dra. Viviane Santos Birchal (UFMG)

Patrocínio

UNIBH

Contatos Revista e-xacta

Endereço

Centro Universitário de Belo Horizonte

Av. Professor Mário Werneck, 1685

Bloco A4 - 3. andar

30455-610 - Belo Horizonte, MG

Telefax: +55 (31) 3319-9209

Endereço Eletrônico

www.unibh.br/revistas/exacta/

exacta@unibh.br

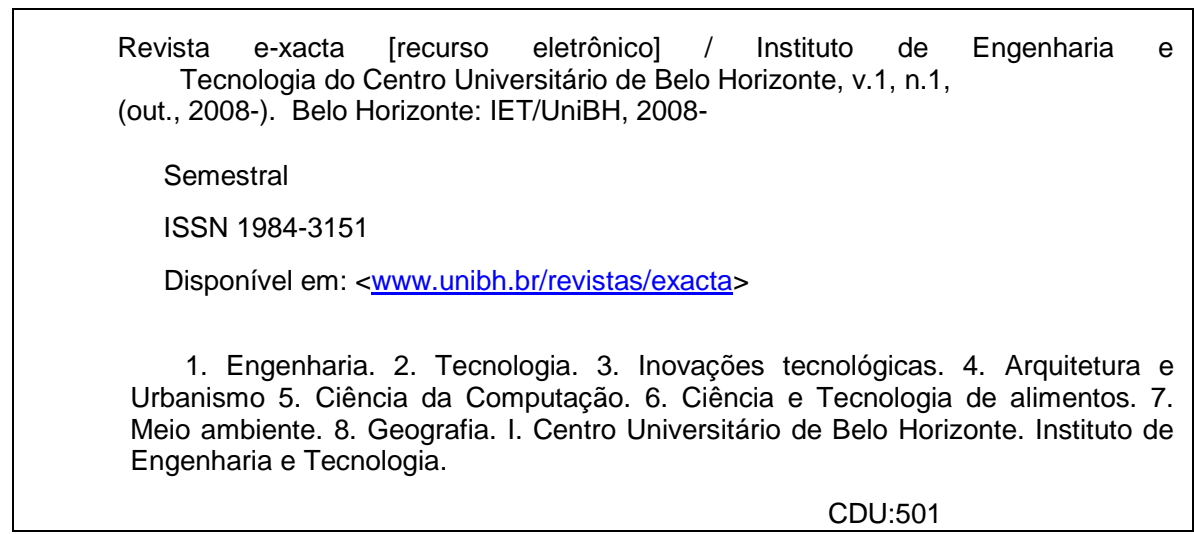

Ficha catalográfica elaborada pela Biblioteca Universitária Ânima 